\title{
BMJ Open Quality Improving donor human milk collection in a hospital without a human milk bank: a quality improvement initiative at an urban tertiary-care teaching hospital
}

To cite: Garegrat R, Malshe N, Suryawanshi P, et al. Improving donor human milk collection in a hospital without a human milk bank: a quality improvement initiative at an urban tertiary-care teaching hospital. BMJ Open Quality 2021;10:e001467. doi:10.1136/ bmjoq-2021-001467

Received 28 February 2021 Accepted 31 May 2021
Check for updates

(c) Author(s) (or their employer(s)) 2021. Re-use permitted under CC BY-NC. No commercial re-use. See rights and permissions. Published by BMJ.

Department of Neonatology, Bharati Vidyapeeth Deemed University Medical College, Pune, India

Correspondence to Dr Suprabha K Patnaik; drsipi@gmail.com

\section{ABSTRACT}

Feed intolerance and necrotising enterocolitis (NEC) are challenges while treating sick neonates. These can be reduced by giving human milk, but adequate availability of mother's own milk or pasteurised donor human milk (PDHM) is a challenge in neonatal setups, like ours, without an attached human milk bank. Hence, this quality improvement initiative was taken to improve donor human milk collection in our urban tertiarycare teaching hospital, to at least $500 \mathrm{~mL}$ per week in 4 weeks. After analysing the problem, our quality improvement team identified a shortage of human milk donation that was due to low awareness among the stakeholders and lack of a system to collect and store human milk and transport it to a milk bank. The team first established a system of supplies needed for milk collection, storage and transportation. It then tested change idea of information, education and counselling to increase milk donation. The team carried out a few plando-study-act cycles (individual and group counsellings, and usage of videos and information leaflets) to test the change ideas and adapted a few and abandoned some. During this journey, the milk collection increased to above the target amount. Various challenges were addressed, and there was a need for constant motivation of the stakeholders, especially the mothers, and now there is sustained milk donation in the setup. This is incorporated in the standard operating procedure and as a quality indicator of the unit for sustaining the changes in the unit. Our initiative can be replicated in other setups for increasing collection of donor human milk. Greater PDHM availability for sick neonates will, in effect, reduce NEC and feeding intolerance rates, leading to reduced hospital stay, morbidity, mortality and economic burden.

\section{PROBLEM}

Feed tolerance and necrotising enterocolitis (NEC) are major concerns for sick neonates, especially those born preterm, who may also face shortage or unavailability of mother's own milk (MOM) in the first few days after birth. In this vulnerable population, pasteurised donor human milk
(PDHM) is needed to initiate and grade up feeds. PDHM reduces the risk of NEC that primarily afflicts preterm infants. ${ }^{1}$ However, PDHM may not be readily available in hospitals that do not have an on-premise human milk bank, such as ours. Hence, we took up a quality improvement initiative to enhance PDHM availability at our 850-bed, urban teaching hospital with a 40-bed neonatal intensive care unit (NICU) that admits 1500 neonates annually but lacks a human milk bank. Half of the neonates admitted to the hospital are born outside the hospital, and the mothers are shifted to this setup after day 3 and later if they are from outside the city. This is variable as per the medical condition of the mothers. This further adds to the challenge of availability of MOM and increases the need for PDHM. Multiple local not-for-profit milk banks provide PDHM for use in our hospital. These banks receive donated milk from our and other hospitals. To improve PDHM availability in our NICU, we undertook an improvement initiative with a goal to raise human milk donation at our hospital rate to $500 \mathrm{~mL}$ per week in 4 weeks. PDHM used in our setup was about $1 \mathrm{~L}$ per week in the 3 months prior to this initiative (13.8 L during August to October 2020 ) and we set a goal of achieving $50 \%$ of this requirement (ie, $500 \mathrm{~mL}$ per week).

\section{BACKGROUND}

The increased risk of feed intolerance and NEC among preterm and sick neonates is a significant cause of neonatal morbidity and mortality. By causing extended hospital stays, they are also economically burdensome to the family. ${ }^{2}$ Both feed intolerance and NEC are prevented by human milk feeding of neonates. ${ }^{3-6}$ As per a recent meta-analysis, human milk consumption compared with 




Figure 1 Process mapping of human milk donation and usage. NICU, neonatal intensive care unit.

formula prevents NEC with a relative risk of $0.62(95 \%$ $\mathrm{CI}=0.42$ to 0.93$).{ }^{7}$ Availability of MOM is an issue in the first few days after child delivery, especially in preterm delivery that shortens the period of preparatory lactogenesis. Additionally, preterm infants may also be less effective at generating the suckling stimulus for lactation. When MOM is in shortage, PDHM is the preferred choice to feed a neonate. ${ }^{8}$ However, the ready availability of PDHM is challenging for neonatal healthcare setups that do not have a human milk bank.

Our neonatal setup, which includes a 40-bed NICU and admits about 1500 neonates every year, does not have an attached human milk bank. Though there are multiple established human banks within the hospital's city, our neonatal setup regularly faces issues related to the availability of PDHM from these banks. This has interfered with starting of feeds and its grading up in sick neonates because of concerns of feed intolerance and NEC in the hospital's neonatal case population. To bridge the demand supply gap of PDHM, we aimed to increase the donor milk collection at our centre, thus increasing the supply of PDHM at the human milk bank. Many quality improvement initiatives have been taken up to improve MOM and PDHM quality and usage in neonates, ${ }^{9-13}$ but none address the issue of increasing donor milk collection from satellite collection centres.

To improve the collection of donor human milk and thereby PDHM availability for sick neonates, we assembled a team of a neonatologist, a neonatology resident, an NICU nurse, a patient ward coordinator and a social worker. Parents and the in-charge of one of the nearby human milk banks were also included in our team. The team got together for brain-storming sessions, interviewed mothers of babies admitted in the NICU and conducted process mapping regarding milk expression and donation (figure 1). Figure 2 depicts the root cause analysis of the problem that the team was attempting to solve. Our team identified among the stakeholders (mothers, healthcare providers and managers) a lack of awareness of milk donation. The hospital lacked a system for the collection, transportation and storage of donor milk.

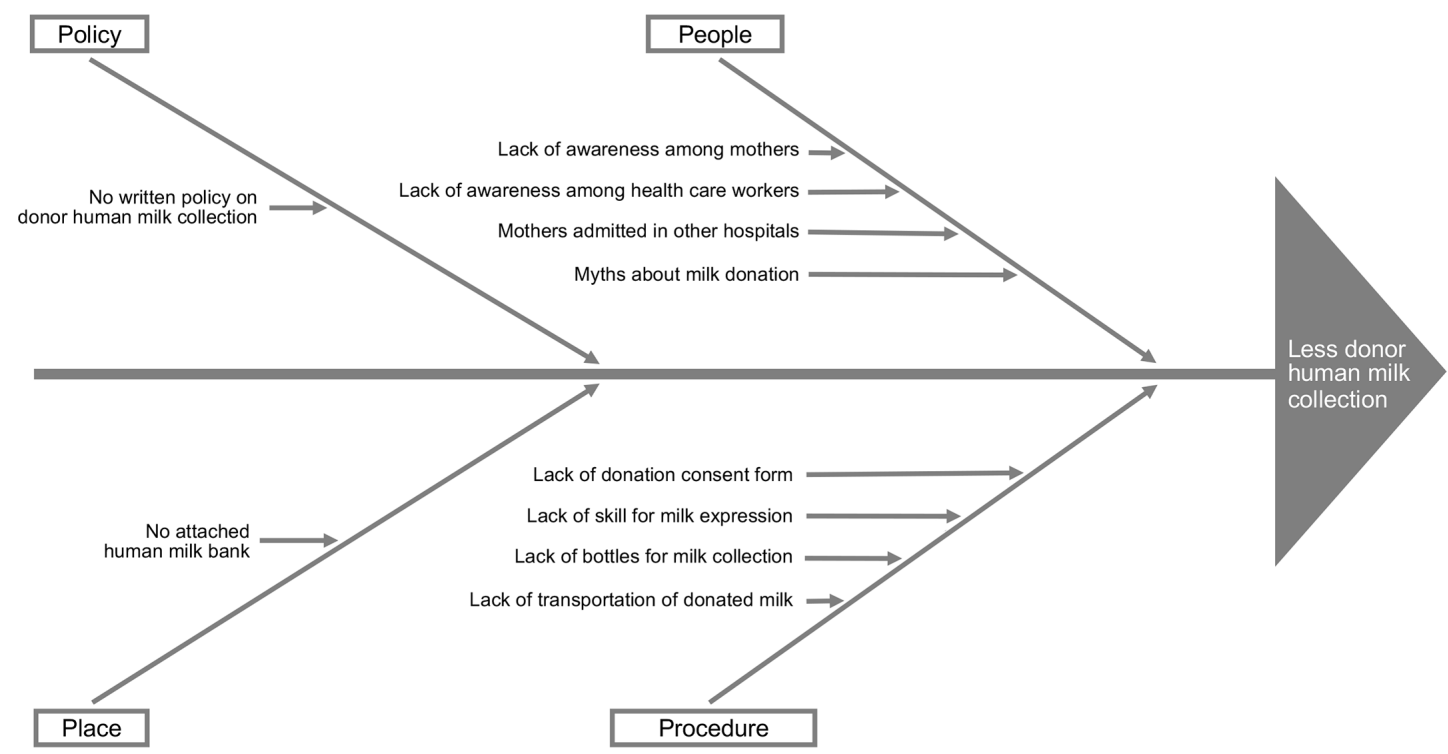

Figure 2 Root cause analysis of low human milk donation. 


\section{MEASUREMENT}

This quality improvement initiative was hence taken up to increase the donor human milk collection at our centre. The quantitative primary endpoint measured was the amount of donor milk collected. We decided to look into NEC incidence rate (stages 2 and 3 ) as the outcome measure. Baseline data on volume of PDHM issued to our hospital by the extramural human milk bank, and donor milk collected by the bank from our setup were collected from the milk bank's electronic records system. The baseline data related to NEC incidence was recorded from the monthly audits of the NICU. Information on NEC is collected in real time in our setup and monthly audits are collated in the first week of the month for the previous month by a neonatology resident. The current process mapping regarding milk donation is shown in figure 1 . NEC stage was assessed from clinical records as per the modified Bell's criteria. The impetus for improving donor human milk collection was to improve the availability of PDHM at the human milk bank. The ward coordinator was responsible for coordinating donor human milk collection and documenting the daily collected amounts. Interventions in the form of counselling were taken as process measure.

\section{DESIGN}

This qualitative study was taken up from November 2020 until February 2021 in the NICU. The team did a gap analysis of the reduced availability of PDHM. The main challenge identified was reduced human milk donation. Root cause analysis of reduced milk donation revealed a lack of awareness regarding milk donation as an important issue among both the mothers and the healthcare workers as human milk bank was not attached to the unit. Also, there was no established system of milk collection and transportation. The team first focused on establishing a system with the human milk bank regarding the availability of bottles and a regular mode of transportation of collected donor milk from the hospital, with all necessary precautions. Also, the bottles' sterilisation was planned, an area for storage of empty sterile and clean bottles was designated and a refrigerator was identified for storage. Since a lot of communication and close coordination was needed, a discussion group on the WhatsApp software for mobile devices was formed for this initiative to keep all stakeholders in the loop. It was decided that the human milk bank will send a vehicle with milk bottles for collection of the donor milk on a need basis and the responsibility of sending the vehicle was on the in-charge of the human milk bank, and the contact person was the ward coordinator at the hospital side. In case of her unavailability, the responsibility was assigned to the social worker of the team. During the meeting, the nature of duties of various members was taken into consideration, and a priority listing of the responsibility was done as per their availability. The meetings helped the team to understand the various roles and responsibilities of the members.
As only healthy mothers can donate milk, medical documents were checked, especially to rule out HIV and hepatitis B infection. The role to check documentation was assigned to the resident doctor posted in the ward. Collection of documentation was performed by the ward coordinator as she was available in the ward and was in constant touch with mothers. A consent form regarding milk donation was developed in the local language, and the responsibility for collecting it after getting it duly signed was assigned to the ward coordinator and the social worker.

After establishing the system of collection and transportation of milk, the next challenge was motivating the mothers to donate the milk. The neonatologist interviewed a few mothers on a one-to-one basis regarding their perception of milk donation and identified lack of awareness, knowledge and information regarding milk donation as gaps. To address this issue, dissemination of the information, education and counselling of the mothers and attendants of the babies admitted in NICU was suggested by the members. The prediction was that with improvement in knowledge, the amount of milk donation would improve. Regarding this change idea, various measures were planned.

\section{STRATEGY}

The team decided to test the change idea of increasing awareness of the stakeholders regarding human milk donation and carried out a few plan-do-study-act (PDSA) cycles as described below.

\section{PDSA cycle 1}

Group counselling of the mothers was the change idea suggested by the members. A structured group counselling was planned to be conducted outside the NICU in its step-down unit. The counselling sessions, of 15-30 min each, were to be held two times a week (Mondays and Thursdays) after the morning round. Counselling responsibility was assigned in the priority order of neonatology resident, physiotherapist, neonatologist, nurse-incharge of the step-down unit and ward coordinator. This ensured that a counsellor was always available. The ward coordinator requested mothers and attendants to join the counselling. In view of the ongoing COVID-19 pandemic, social distancing was maintained during the counselling sessions and face masks were used. The timing of the counselling was decided to have maximum participation of the stakeholders. On interviewing the mothers and the nursing staff working in the areas, morning hours were found to be suitable for counselling, as mothers would be resting in the afternoon, and in the evening, they would have visitors. The ward coordinator maintained counselling records in the wards' register, and she compiled data summaries every week (figure 3). A WhatsApp group was used to establish the availability of persons for conducting the counselling sessions. The prediction with this PDSA was that $75 \%$ of the mothers and attendants would attend 


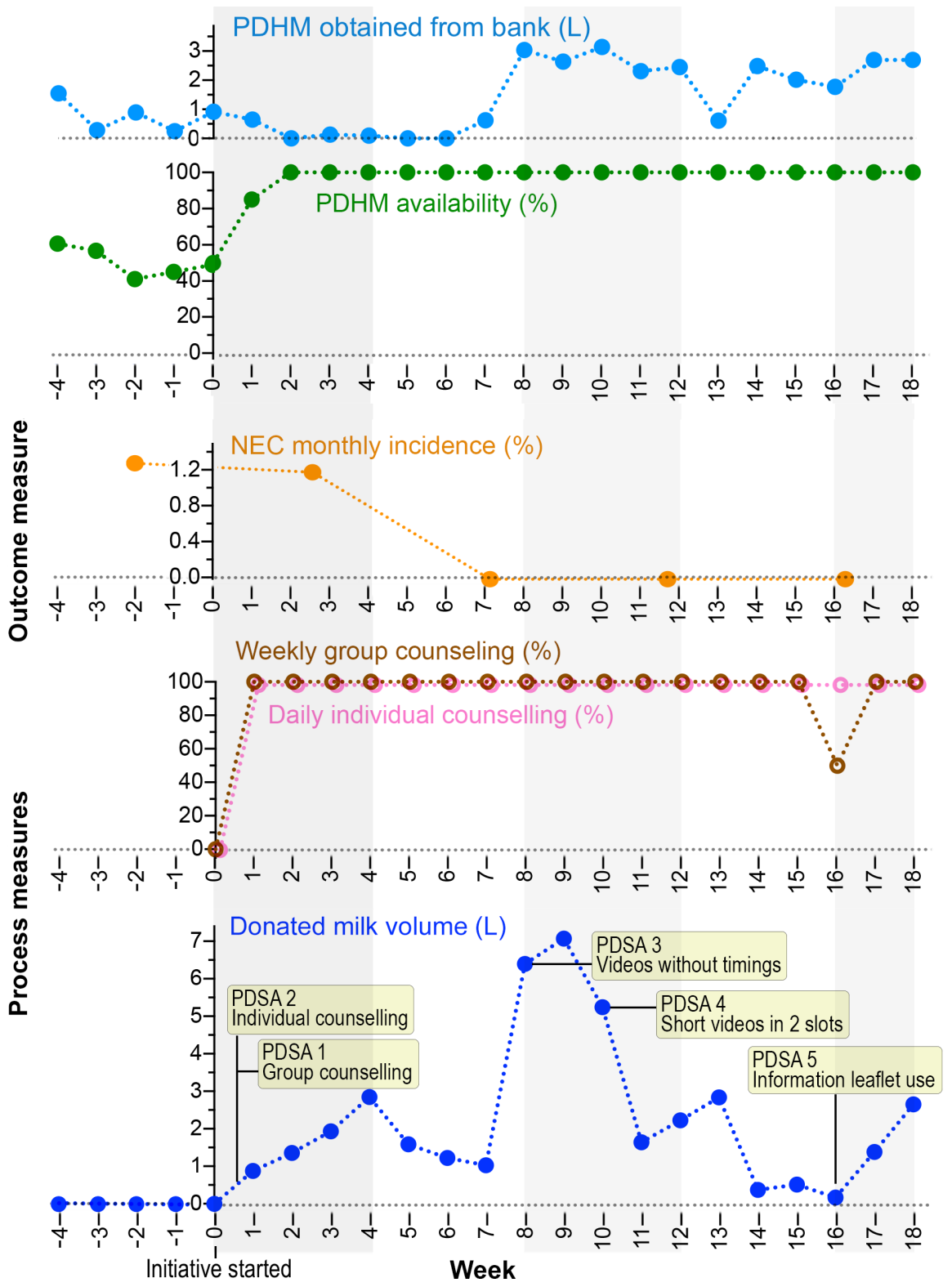

Figure 3 Time series chart of outcome and process indicators. The quality improvement initiative was started at time 0 . PDHM availability is the percentage of PDHM need that could be obtained from the milk bank. NEC, necrotising enterocolitis; PDHM, pasteurised donor human milk; PDSA, plan-do-study-act.

the session, and there will be availability of the person for group counselling. With the counselling, the mothers will be motivated to donate the extra breast milk they have. The group counselling sessions were also attended by the nursing staff and the resident doctors. This opportunity was used to improve the knowledge regarding the donation of human milk and the procedure. This was tested for a week (two sessions), and there were no challenges as 12 of 15 mothers attended the first session. Two mothers could not attend as they had other medical appointments, and one was giving kangaroo mother care to her baby. Thirteen of 16 mothers attended the next session. Feedback from the mothers regarding the session was positive and they found the sessions to be meaningful and felt motivated to donate milk. The idea of this PDSA was therefore adopted.

\section{PDSA cycle 2}

To reinforce information and motivation, daily oneto-one structured counselling by the team members was planned. This responsibility was voluntarily taken up by the ward coordinator and the social worker. These personnel met all the parents daily and counselling could be incorporated into their meetings. The prediction was that individual counselling would reinforce the value of donation of excess milk by mothers, thus leading to more milk collection. A concern was that though the coordinator/social worker will be able to meet the mothers, this might interfere with her routine ward work. In addition, there was concern about counselling on holidays. It was decided that on holidays or on days when the ward coordinator or social worker were not available, the ward's nursing staff will do the counselling. As there are many 
myths about milk expression in the community, such as milk donation causing a reduction in milk production for the baby, individual counselling was considered an opportunity to alleviate such worries. Also, milk donation being a matter of perception and motivation, the team felt the need for more counselling as an intervention. This was tested for 3 days, during which 42 mothers were individually counselled, and the counsellor did not face any difficulty and could also carry out her routine ward responsibilities. The idea of this PDSA was therefore adopted.

\section{PDSA cycle 3}

The team came up with the idea of using audio-visual aids in the form of videos for imparting knowledge regarding benefits of human breast milk and its donation, including methods for expressing milk. Pre-existing videos, each of approximately $15-25 \mathrm{~min}$, that had been created by the Breastfeeding Promotion Network of India $^{14}$ were used. They were displayed on an existing television in the step-down unit with the help of hospital's information and technology personnel. The timing for playing the videos was a challenge. For 3 days, they were played in the morning after the morning rounds, and for 3 days, they were played in the evening for an hour. The prediction was that the mothers and their visiting relatives would watch them. However, only a few people ( 5 of 16 mothers) watched the videos in full as others thought they were too long. Feedback from them revealed that the videos were found to be noisy and interfering with their resting time. Hence, the idea of this PDSA was adapted as it was decided to play the videos for only 15-20 min and in two slots.

\section{PDSA cycle 4}

Videos on expression and donation of human milk were played in the ward for only 15-20 min during 11:3012:30 and 16:00-17:00, which were deemed as optimal viewing times considering consultant rounds, relative visiting hours and patient meal and resting times. The responsibility was assigned to the ward coordinator for the morning video display and the ward nurse for the evening display. The prediction was that the videos would be watched with interest by the mothers and attendants, and that the ward coordinator and nursing staff will be able to display them on schedule. This data were to be collected and documented in the same register. It was observed that very few mothers (2 of 14) were interested in the videos. Many thought the videos were too loud. Mothers felt that they did not have time for the videos as they had to take care of the baby and also rest. Hence, after a week's review, this change idea was abandoned.

\section{PDSA cycle 5}

As many of the admitted sick babies at the hospital were born elsewhere and their mothers were admitted in a different hospital, the team felt the need to provide information regarding milk expression and donation to the attendant present in our hospital. An information sheet on the expression and donation of excess human milk was created in the local language by the neonatology resident. The responsibility of giving the information orally and the sheet to the neonate's attendant was assigned to the staff nurse. The nurse did so after the doctor's initial counselling regarding the medical condition of the baby or after the morning counselling of parents/attendants by the treating neonatologist but within 24 hours of admission of the baby to the unit. This was studied for the next 3 days. The ward coordinator collected data on this. The concern was that the nurse might forget to give the sheet or the attendant might not read it. However, the team could perform its task for all four babies admitted during the time. The ward coordinator and the social worker took feedback from the attendants and nurses regarding this concern and concluded that neither occurred. The team, therefore, adopted this change idea.

The team met every week for a short update on the initiative and to discuss challenges that were being faced. Regular sharing of the data that indicated continual progress kept the team spirits high. With the interventions, a focused action plan and a larger interest in improving PDHM availability and reducing NEC incidence, the team achieved the goal of increasing the collection of donor milk from mothers in our setup (figure 3). There was no additional cost involved in this process. Parents whose babies had received PDHM were more than happy to donate their excess milk. To encourage milk donation, which needs psychological preparation, a notice board has been placed in the step-down unit with a message thanking mothers for this noble cause.

\section{RESULTS}

With the interventions of structured counselling (individual and group), donor milk collection increased from $0 \mathrm{~mL}$ a week during the month prior to the initiative to $880 \mathrm{~mL}$ after the first week and a maximum of $7070 \mathrm{~mL}$ after the ninth week of the initiative (figure 3). There were fluctuations in milk collected due to various human factors like number of babies admitted, number of mothers having extra milk for donation, their motivation and willingness to donate and their family support. During the 14th and 15th weeks, there was a reduction in milk collection because there were fewer neonate admissions. After collection, donated milk was supplied to the milk bank, which in turn provided PDHM as per the NICU's requirement. Following initiation of our project, PDHM availability (percentage of NICU need fulfilled by the milk bank) also improved, from $40 \%-65 \%$ in the prior 1 month to $100 \%$ after the second week of the initiative. As expected, improved PDHM availability was associated with a reduction in NEC incidence. The monthly incidence of NEC (stages 2 and 3) among babies admitted in the unit came down to zero by the second month of intervention from the baseline of $1.2 \%$. In the 16 th week, only individual counsellings were done and group counselling did not take place as there were very 
few patients. As shown in figure 3, this likely resulted in reduced milk donation, despite the videos being shown.

\section{LESSONS AND LIMITATIONS}

This improvement initiative and its results taught us the importance of all stakeholders' collaborative efforts and to anticipate the variability of persons availability assigned to a specific role. Having a priority listing of the role assigned for a given task helped the team do the interventions smoothly, and the periodic review meetings helped move forward the learning from the feedback. During this process, the team learnt that all efforts might not yield the desired result, as evidenced from PDSA 4. Feedback from the stakeholders is necessary for any successful intervention. Understanding human psychology of change and physical limitations help in designing better plans for the interventions. Here, the team did a lot of groundwork to develop the timing of various interventions as we wanted the full attention of our mothers and attendants, who were already emotionally and physically drained. This initiative's limitation is a lot of emphasis on human elements such as counselling, driving force and motivation. Nevertheless, milk donation per se has a major psychological involvement, thus addressing that component is vital. There has not been a shortage of PDHM for the neonates who need it since the project was initiated. There is a regular feedback mechanism from the human milk bank, and the positive feedback has kept the team spirit high. Sustainability of these interventions should be possible as now it has become a part of working and is also included in the NICU's standard operating procedure and is one of the unit's quality indicators. The stocking bottles for collecting expressed milk, freezing collected milk and transporting the frozen stocks to the outside human milk bank are now streamlined and wellestablished at our hospital.

\section{CONCLUSION}

There is a proven need for PDHM for preterm and sick neonate for risk reduction of a dreadful complication like NEC, which not only has a high mortality but also has longterm morbidity in domains including neurocognition. This improvement initiative's objectives were to increase the collection of donor human milk from the neonatal ward of a hospital that lacked a human milk bank and establish a system of collection and transportation of the donor milk to a nearby human milk bank. The initiative led to improved availability of PDHM, thus reducing one of the factors contributing towards NEC in the hospital's neonatal setup. The focused team effort with multiple PDSAs and the learnings from them helped achieve the aim of increased donor human milk collection. The team is now attempting to improve donor human milk collection from the hospital's postnatal ward. Mothers admitted in the postnatal ward typically stay there for only a few days. The short duration of stay will be a significant challenge in this effort because of uncertain or limited milk production in the immediate post-delivery period.

India has about two dozen human milk banks, and there is a focus on comprehensive lactation management centres. They do not meet the demand for PDHM that is necessitated by the high burden of premature births in the country. Thus, there is a clear need to establish donor human milk collection centres in both public and private sectors along with increasing human milk banks. We hope that the lessons of our initiative will be valuable towards such efforts.

Acknowledgements We thank the mothers and attendants for participating in this initiative. We thank Mrs Archana, sister-in-charge; Mrs Amruta Bhoite; Mrs Swati; Dr Puja P; Dr Gazala Khan (in-charge, Yashoda Human Milk Bank, Pune) for their active participation. We also thank Nationwide Quality of Care Network (NQOCN), India, for encouraging this work and guidance during manuscript preparation.

Contributors All four listed authors certify that they have participated sufficiently in the work and take public responsibility for the content. Project conception and supervision was provided by SKP. Design and acquisition of data were undertaken by NM, PS, RG and SKP. Analysis and interpretation of data were done by RG and SKP. Drafting of the manuscript was undertaken by SKP, while its editing was completed by NM, PS and RG. All authors approved the final manuscript.

Funding The authors have not declared a specific grant for this research from any funding agency in the public, commercial or not-for-profit sectors. Publication of this article is made Open Access with funding from the Nationwide Quality of Care Network.

Competing interests None declared.

Patient and public involvement Patients and/or the public were involved in the design, or conduct, or reporting, or dissemination plans of this research. Refer to the Methods section for further details.

Patient consent for publication Not required.

Provenance and peer review Not commissioned; externally peer reviewed.

Data availability statement All data relevant to the study are included in the article.

Open access This is an open access article distributed in accordance with the Creative Commons Attribution Non Commercial (CC BY-NC 4.0) license, which permits others to distribute, remix, adapt, build upon this work non-commercially, and license their derivative works on different terms, provided the original work is properly cited, appropriate credit is given, any changes made indicated, and the use is non-commercial. See: http://creativecommons.org/licenses/by-nc/4.0/.

\section{REFERENCES}

1 Lu AS, Harrison CM. Formula feeding results in better growth and weight gain compared to donor breast milk in preterm and low birthweight infants, with a greater risk in necrotising enterocolitis. Arch Dis Child Educ Pract Ed 2020;105:381-2.

2 Johnson TJ, Berenz A, Wicks J, et al. The economic impact of donor milk in the neonatal intensive care unit. $J$ Pediatr 2020;224:57-65.

3 Cañizo Vázquez D, Salas García S, Izquierdo Renau M, et al. Availability of donor milk for very preterm infants decreased the risk of necrotizing enterocolitis without adversely impacting growth or rates of breastfeeding. Nutrients 2019;11. doi:10.3390/nu11081895. [Epub ahead of print: 14 Aug 2019].

4 Miller J, Tonkin E, Damarell RA, et al. A systematic review and metaanalysis of human milk feeding and morbidity in very low birth weight infants. Nutrients 2018;10. doi:10.3390/nu10060707. [Epub ahead of print: 31 May 2018].

5 Quigley M, Embleton ND, McGuire W. Formula versus donor breast milk for feeding preterm or low birth weight infants. Cochrane Database Syst Rev 2019;7:CD002971.

6 Zhang B, Xiu W, Dai Y, et al. Protective effects of different doses of human milk on neonatal necrotizing enterocolitis. Medicine 2020;99:e22166. 
7 Altobelli E, Angeletti PM, Verrotti A, et al. The impact of human milk on necrotizing enterocolitis: a systematic review and meta-analysis. Nutrients 2020;12:1322.

8 Meeks M, Franks A, McGregor H, et al. Supporting mothers, protecting babies for long-term health: establishing a pasteurised human milk bank. N Z Med J 2019;132:83-91.

9 Alshaikh B, Kostecky L, Blachly N, et al. Effect of a quality improvement project to use exclusive mother's own milk on rate of necrotizing enterocolitis in preterm infants. Breastfeed Med 2015;10:355-61.

10 Ferrarello D, Schumacher A, Anca R. Nurse-driven initiative to increase exclusive human milk feeding by using pasteurized donor human milk to treat hypoglycemic term neonates. Nurs Womens Health 2019;23:316-26.
11 Kalluri NS, Burnham LA, Lopera AM, et al. A quality improvement project to increase mother's milk use in an inner-city NICU. Pediatr Qual Saf 2019;4:e204.

12 Oza-Frank R, Kachoria R, Dail J, et al. A quality improvement project to decrease human milk errors in the NICU. Pediatrics 2017;139. doi:10.1542/peds.2015-4451. [Epub ahead of print: 11 Jan 2017].

13 Ward L, Auer C, Smith C, et al. The human milk project: a quality improvement initiative to increase human milk consumption in very low birth weight infants. Breastfeed Med 2012;7:234-40.

14 Guidelines for lactating mothers: breastfeeding promotion network of India. Available: https://bpnimaharashtra.org/resources-for-mothers/ videos [Accessed 2 May 2021]. 